\title{
Emotional abuse towards children by schoolteachers in Aden Governorate, Yemen: A cross-sectional study
}

\author{
Amal S S Ba- Saddik ${ }^{1^{*}}$ and Abdullah S Hattab ${ }^{2^{*}}$
}

\begin{abstract}
Background: Emotional abuse is central to other forms of abuse. The primary objective of this paper was to estimate the prevalence of emotional abuse among pupils in basic education schools and the risk factors associated with it in Aden governorate, Yemen.
\end{abstract}

Methods: Four districts were randomly selected from across the governorate of Aden, 2 schools were selected at random in each district, and then 1066 pupils were randomly selected from the 8 schools. An anonymous self-administered questionnaire was used for data collection. Data were analyzed using Statistical Package for Social Sciences ver.15. Mean, standard deviation and chi square were used for descriptive statistics. Univariate and Multivariate logistic regression analysis was used to examine the associations between emotional abuse with pupils/parents characteristics.

Results: Pupils reported high rates of emotional abuse $55.2 \%$ at least once in their school lifetime. Male pupils had higher prevalence of emotional abuse $72.6 \%$ than females $26.1 \%$. Teachers constituted the highest proportion of perpetrators $45.6 \%$. Odds Ratio (95\% confidence interval) showed statistically significant association between emotional abuse and pupils' gender, family type and father education: 9.94 (7.19-13.74), 1.40 (1.02-1.91), .58 (.39-.86) respectively.

Conclusion: Emotional child abuse was highly prevalent in pupils in basic school education. Pupils' gender, family type and father education were the main risk factors associated with emotional abuse.

Keywords: Emotional abuse, Teachers, Schoolchildren, Aden

\section{Background}

Emotional abuse may be the most prevalent type of child abuse; however, it is also the most hidden, underreported, and least studied type of abuse [1,2]. Literature on emotional abuse is limited, which could be attributed to the fact that it is the most difficult form of abuse to research, because of lack of a consistent definition, detect, assess, and substantiate [2].

A growing body of research highlights the harmful effects of emotional maltreatment in children. As such,

\footnotetext{
* Correspondence: abasaddik@gmail.com; abdullahattab@gmail.com 'Department of Behavioral Sciences, Faculty of Medicine \& Health Sciences, Aden University, P.O. Box 6165 (Khormaksar), Aden, Yemen

${ }^{2}$ Department of Social Medicine \&Public Health, Faculty of Medicine \&Health Sciences, Aden University, P.O. Box 6165 (Khormaksar), Aden, Yemen
}

victims experience difficulties in terms of physical health and neurophysiological, emotional, behavioral, and cognitive development [3]. Also, it is significantly related to subsequent delinquent behavior and academic difficulties in early adolescence [4].

Many psychologists assert that emotional abuse is the most devastating form of child abuse, because of its traumatic effects in the development of school pupils $[2,5,6]$, and it underlies all types of child abuse as a perpetrator of emotional abuse can abuse many victims at one particular moment [7].

To date, studies on pupils' abuse by teachers are relatively limited and those that exist mainly focus on corporal punishment [8-10]. Nevertheless, high prevalence of emotional child abuse was reported from India, United States, Zimbabwe, Nigeria and Cyprus [11-15]. The

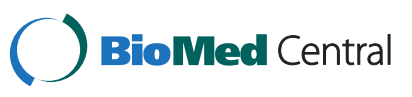


study from India found that $47.9 \%$ of surveyed boys and $52.1 \%$ of girls had experienced emotional abuse in schools [11].

It is important to explore the issue of pupils abused by educators in educational settings in the Eastern Mediterranean regions, since only two studies $[16,17]$ have indicated that pupils' abuse in schools was enormous. In Bahrain, Al-Mahrous in 1997 found that emotional abuse was very frequently reported by girls $78 \%$ [16], while a study from Iran showed that emotional abuse among schoolgirls was 49.8\% [17].

In Yemen, documented studies on child abuse are very scarce. Nevertheless, literature search revealed two important studies that addressed the problem of child abuse in family setting $[18,19]$. The third one [20] was more comprehensive covering the problem of child abuse in family, community and school setting and showed that $42.3 \%$ of the school pupils experienced humiliating as an undesirable emotional behavior by their teachers.

This study aimed to assess the prevalence of emotional abuse among schoolchildren in Aden schools and associated factors. Also, we expect that it will contribute to better understanding of emotional abuse in school setting in a developing country.

\section{Methods}

\section{Study design and setting}

This study is a part of a more comprehensive crosssectional survey of different types of abuse among schoolchildren of basic education in Aden Governorate in Yemen that was conducted during the school year 2009-2010.

\section{Study population}

Pupils of grades 7, 8 and 9 were targeted in the survey. Children, at the age of 12-17 years, usually are capable of perceiving what is and is not abuse within the school context, they also could provide reliable information, and are capable of answering the questionnaire $[10,21]$.

\section{Sample size}

The sample size was calculated using the assumed proportion of 0.5 in order to obtain the maximum possible sample size, with a level of confidence $95 \%$, and 0.03 , as maximum allowable error. Accordingly, the calculated sample size was 1066 pupils who were proportionally distributed according to pupils' gender (667 males and 399 females).

\section{Sampling method}

A multi-stage stratified random sampling was performed. In the first stage, four districts were randomly selected. In the second stage, two schools from each district also were randomly selected. In the third stage, the sample size (1066) was proportionally distributed according to the proportion of students in the selected grades for each school by gender. The sample frame for this study was the pupils' list in the selected grades of the schools incorporated in this study. Systematic random sampling was applied to select the number of pupils assigned for each grade in the selected schools.

\section{Instrument}

An anonymous self-administrated questionnaire adapted from the Arabic version of Child Abuse Screening Tool Children's Institutional Version [21], was used for data collection.

The first part of the instrument covers questions about pupil's variables: gender, age, school grade, residence, in addition to parent's socio-demographic variables: family type, parent's education and parent's marital status.

The second part includes 10 items including acts such as humiliating, shouting, calling names, embarrassing them of being orphan, poor, having health problems, threatening with giving them bad marks, or expelling from school, isolating them from other children and destroying their belongings.

Experts in child abuse from Yemeni Universities judged the questionnaire, to find out if it is socially acceptable. Accordingly, some items were rephrased, and other items were dropped out. The final modified version of the questionnaire used in this study included the following questions:

Have you ever been exposed to any of these acts at school?

Humiliating, shouting, calling names, embarrassing of being orphan, embarrassing of being poor, threatening with bad marks, threatening to expelling from school, embarrassing for having health problems, isolating from children, destroying belongings. Pupils who answered with "Yes" were asked to report the frequency of the abuse acts by indicating 1-2 times, 3-4 times, $\geq 5$ times. In addition they were asked to mention who did it: a teacher or a school administrator? [21].

\section{Pilot study}

A pilot study was conducted among 60 pupils (30 males and 30 females) from two schools not included in the main study, to ensure that the questionnaire items were clear, understandable and culturally acceptable. Chronbach alpha was used to test the internal consistency reliability, which was found to be 0.78 .

We explained the questionnaire in detail to the pupils, and asked them to answer 'yes' or 'no' to each item and how many times they have experienced abusive acts during scholastic years. Those who responded affirmatively were asked to identify the perpetrators: teacher or school 
administrative staff. The rate of physical abuse was calculated by recoding the acts into dichotomous categories, with $0=$ never and $1=$ once or more [22]. A 4point scale ( $0=$ none; $1=1-2$ times; $2=3-4$ times; $3=$ 5 times and more) was used to indicate how often they had experienced each abuse act [23].

\section{Operational definition}

Emotional abuse in this study refers to pupils' reports of any undesirable or unpleasant emotional act inflicted on them by teachers or other school administrators (school principal, vice principal or other workers) which could potentially make them feel embarrassed while in school. Emotionally abused pupils were defined as those who answered positively to one or more of the emotional abuse acts.

\section{Ethical considerations}

1. The research protocol was approved by the Committee of Research and Postgraduate Studies in the Faculty of Medicine and Health Sciences, Aden University. Several levels of permission were granted before the study could proceed, including official approval from the authority of Aden Education Office. In addition, permission was sought from the Districts Directors of Education, as well as from school principals.

2. A written informed consent was sent to the pupils' parents describing the nature of the study, its importance, and its objectives. The consent also stated that the data's confidentiality would be assured, that the participation in the study was voluntary and those who refused participation will not lose any rights or privilege. Parents were asked to put their signature if they agree to have their child participate in the survey. The response rate was $85 \%$ of the targeted parents. For those who declined to consent, equal number was substituted following the same methodology.

3. The pupils' informed assent was obtained orally during which detailed explanation of the objectives and the importance of the research was provided. Potential participants were assured that all information obtained will be handled confidentially. Pupils were informed that they have the right to decline answering any question and/or to withdraw from the study at any time. All pupils whose parents gave consent to their participation have assented to participate in the study.

\section{Data analysis}

The Statistical Package for Social Science -SPSS - version 15 was used for data analysis. Quantitative variables were normally distributed after testing for normality using Kolmogorove-Smirnov test. Percentage was calculated as summary measure for the qualitative variables. Arithmetic mean, standard deviation and chi square test were used for the descriptive statistics. The statistical significant level was set at p-value $<0.05$.

Binary logistic regressions were conducted to describe the bivariate association between emotional abuse and the pupils and parents variables. Multivariate analysis was performed to identify risk factors associated with emotional abuse. The results were discussed in terms of the odds ratio (OR) with 95\% Confidence Interval (CI). The OR of the reference category is equal to " 1 ". If an OR is greater than "1" this indicates an increase likelihood of the event (emotional abuse in this research) occurrence, while an OR less than "1" indicates a decreased likelihood of its occurrence.

\section{Results}

\section{Socio demographic characteristics of the study} population

Table 1 shows the socioeconomic characteristics of the study population. Male pupils constituted the highest proportion $62.6 \%$. The mean age was $14.03 \pm 1.13$ years. Most of the pupils lived in nuclear families. More than $50 \%$ of the mothers were illiterates or could only read and write.

\section{Prevalence of emotional abuse}

The study sample included 1066 pupils: 588 of them reported one or more emotional abuse acts, before the age of 18 years. The prevalence of emotional abuse in the surveyed sample was $55.2 \%$ (95\% CI: 52.1 - 58.2). Teachers occupied the higher proportion of being responsible for emotional abuse $45.6 \%$, followed distantly by the administrative staff $5.0 \%$. As summarized in Table 2. The most common emotional abuse act reported by pupils was shouting $48.1 \%$, the next most common emotional abuse acts were calling names $36.1 \%$ and threatening to give bad marks 31.9\%. The lowest emotional abuse acts the pupils experienced was being embarrassed by teachers and school administrators for being an orphan $1.7 \%$ and $2.0 \%$ reported being threatened that their belongings will be destroyed. However, it is important to note that there are gender statistically significant differences: Males had higher prevalence rates than females on almost all of the acts of abuse.

The frequency of emotional abuse acts is presented in Table 3. Abuse acts that were experienced 1-2 times were shouting $20.7 \%$, threaten to drop out school $16.9 \%$ and calling names $15.0 \%$. On the other hand, those acts that were experienced 3-4 times were shouting $12.1 \%$, calling names $8.3 \%$, and threaten with bad marks $8.2 \%$. While those acts that were experienced five times or 
Table 1 Distribution of pupils and their families by sociodemographic characteristics

\begin{tabular}{|c|c|c|}
\hline Pupils characteristicsllr & No. & $\%$ \\
\hline \multicolumn{3}{|l|}{ Gender } \\
\hline Male & 667 & 62.6 \\
\hline Female & 399 & 37.4 \\
\hline \multicolumn{3}{|l|}{ Age group (years) } \\
\hline $12-13$ & 363 & 34.0 \\
\hline $14-15$ & 618 & 58.0 \\
\hline $16-17$ & 85 & 8.0 \\
\hline \multicolumn{3}{|c|}{ Mean age $=14.03 \pm 1.13$ years } \\
\hline \multicolumn{3}{|l|}{ School grade } \\
\hline Grade 7 & 322 & 30.2 \\
\hline Grade 8 & 366 & 34.3 \\
\hline Grade 9 & 378 & 35.5 \\
\hline \multicolumn{3}{|c|}{ Family socio-demographic characteristics } \\
\hline \multicolumn{3}{|l|}{ Family type } \\
\hline Nuclear & 747 & 70.1 \\
\hline Extended & 319 & 29.9 \\
\hline \multicolumn{3}{|l|}{ Parents marital status } \\
\hline Married & 952 & 89.3 \\
\hline Separated & 21 & 2.0 \\
\hline Divorced & 33 & 3.1 \\
\hline Widow & 60 & 5.6 \\
\hline \multicolumn{3}{|l|}{ Father education } \\
\hline Illiterate & 74 & 6.9 \\
\hline Read and write & 281 & 26.4 \\
\hline Basic & 103 & 9.7 \\
\hline Secondary & 202 & 18.9 \\
\hline University & 406 & 38.1 \\
\hline \multicolumn{3}{|l|}{ Mother education } \\
\hline Illiterate & 264 & 24.8 \\
\hline Read and write & 324 & 30.4 \\
\hline Basic & 177 & 16.6 \\
\hline Secondary & 162 & 15.2 \\
\hline University & 139 & 13.0 \\
\hline
\end{tabular}

more were shouting $15.3 \%$, calling names $12.8 \%$ and humiliating $9.6 \%$.

\section{Association analysis Univariate analysis}

Table 4 shows the association of the pupils' sociodemographic factors with emotional abuse. Gender and age group have a significant association with emotional abuse. Male had a significantly higher odd of experiencing emotional abuse $(\mathrm{OR}=7.50 ; \mathrm{CI}: 5.66$ - 9.93) than females. With respect to the age group, emotional abuse significantly increases at the age group 16-17 years $(\mathrm{OR}=1.91$; 95\%CI: 1.17-3.11). The univariate analysis does not show any significant association between school grade and emotional abuse.

Table 5 illustrates that pupils living in extended families were more likely to experience emotional abuse $(\mathrm{OR}=1.55 ;$ 95\%CI: 1.18-2.03). Concerning parents' marital status, only pupils with divorced parents were significantly more likely to experienced emotional abuse $(\mathrm{OR}=2.20$; CI: 1.01-4.79). On the other hand, the high education levels of fathers play a protective role against pupils' emotional abuse (OR $=.64$; 95\%CI: .46-.90).

\section{Multivariate analysis of predictors of emotional abuse}

All the variables that were significant in the univariate models with a $\mathrm{p}$ value $<0.05$ were entered into the backward logistic regression. The final multivariate logistic regression models included all variables retaining significant after adjusting for each other. As can be seen in Table 6 the significant predictors were male gender, family type and father education. Male pupils had about ten times greater risk of experiencing emotional abuse $(\mathrm{OR}=9.94 ; \mathrm{CI}: 7.19-13.74)$ than female. On the other hand, a protective association was found among pupils belonging to highly educated fathers $(\mathrm{OR}=.58$; CI: .39-.86).

\section{Discussion}

This study is the first in Aden to explore the issues related to pupils' reports of emotional abuse in the school context. This study was conducted to describe the prevalence of emotional abuse by teachers and administration staff in schools. In addition, it provides empirical evidence on how pupils and parents sociodemographic characteristics were associated with pupils' victimization by school staff in Aden governorate.

It is often assumed that the consequences of emotional abuse are not as severe as those of more obvious forms of abuse [24], but in fact, relatively little is known about the magnitude of the problem of child emotional abuse worldwide. The prevalence of emotional abuse in the current study was $55.2 \%$; it was relatively lower than that found in Iran 59.9\% [17], but higher than that reported in Cyprus 33.1\% [15] and Taiwan 11.6\% [23]. Prevalence rates of emotional abuse are difficult to ascertain because they capture a wide range of teaching behaviors, and there is little, or no consensus across studies as to what phenomena should be included. The observed differences between countries could be examined from several perspectives. First, it might be that the overall teacher behavior in the various countries is genuinely different, and emotional abuse of pupils was frequently noted as a means of controlling the classroom [25]. 
Table 2 Distribution of emotional abuse acts by gender

\begin{tabular}{|c|c|c|c|c|c|c|c|}
\hline \multirow[t]{3}{*}{ Emotional abuse acts } & \multicolumn{6}{|c|}{ Gender } & \multirow[t]{3}{*}{$P$-value } \\
\hline & \multirow{2}{*}{\multicolumn{2}{|c|}{$\begin{array}{c}\text { Male } \\
(n=667)\end{array}$}} & \multirow{2}{*}{\multicolumn{2}{|c|}{$\begin{array}{c}\text { Female } \\
(\mathrm{n}=399)\end{array}$}} & \multirow{2}{*}{\multicolumn{2}{|c|}{$\begin{array}{l}\text { Total } \\
1066\end{array}$}} & \\
\hline & & & & & & & \\
\hline Humiliating & 221 & 33.1 & 82 & 20.5 & 303 & 28.4 & 0.000 \\
\hline Shouting & 351 & 52.6 & 162 & 40.6 & 513 & 48.1 & 0.022 \\
\hline Calling names & 290 & 43.5 & 95 & 23.8 & 385 & 36.1 & 0.000 \\
\hline Embarrassed of being orphan & 17 & 2.54 & 1 & 0.3 & 18 & 1.7 & 0.005 \\
\hline Embarrass of being poor & 51 & 7.6 & 6 & 1.5 & 57 & 5.3 & 0.000 \\
\hline Threaten with bad marks & 242 & 36.3 & 98 & 24.6 & 340 & 31.9 & 0.003 \\
\hline Threaten to drop out school & 268 & 40.2 & 65 & 16.3 & 333 & 31.2 & 0.000 \\
\hline Embarrass by having health problems & 38 & 5.7 & 14 & 3.5 & 52 & 4.8 & 0.125 \\
\hline Isolated from children & 59 & 8.8 & 15 & 3.8 & 74 & 6.9 & 0.002 \\
\hline Destroying belongings & 19 & 2.8 & 2 & 0.5 & 21 & 2.0 & 0.008 \\
\hline
\end{tabular}

Second, emotional abuse might be conceptualized differently in these countries, and what "falls outside the range of acceptability" is variously defined [26]. Third, the methodology used, the study population, and the timing frame are not the same for all studies. Finally, cultural context could differently influence the perception of the abuse acts, where a lot of acts might be culturally accepted ways of disciplining pupils and are therefore not perceived to be abuse acts by a teacher or school administrators $[11,27]$.

In our study, the relatively high frequency of teachers' emotionally abusive behavior could be explained by different social, cultural, and organization factors. For example, some abusive behaviors might be culturally acceptable, such as "shouting and calling names". On the other hand, teachers might not be fully aware about child rights in addition to lack of comprehensive disciplinary rules concerning the appropriate management of pupils.

The current study indicates that males had significantly higher odds of experiencing emotional abuse than females, which is consistence with previous studies $[15,17,28]$. This could be interpreted by the fact that boys are more likely to have a conflicting relationship with their teachers than their female counterparts $[29,30]$. Interestingly, inattention seemed to provoke the teacher's scorn, especially for boys but not for girls. One possible explanation may be that, in girls, a lack of attention may be considered a temporary lapse and thus, be more readily excused or ignored than in boys. In line with this notion, low-achieving boys have been shown to have been treated more negatively by teachers than their female counterparts [4]. On the other hand, it has been noticed that male pupils are more involved in disruptive behaviors in the classroom, such as noise, shouting, fighting and throwing up, to get attention compared to girls. This may prompt teachers to emotionally abuse boys more than girls. Moreover, it was concluded that, compliance, following rules and being neat and orderly, is valued and reinforced in many classrooms. In addition, they stressed that these are behaviors, which are typically associated with girls rather than boys, and

Table 3 frequency of emotional abuse acts

\begin{tabular}{|c|c|c|c|c|c|c|c|c|}
\hline \multirow[t]{2}{*}{ Emotional abuse acts } & \multicolumn{2}{|c|}{ Never } & \multicolumn{2}{|c|}{ 1-2 times } & \multicolumn{2}{|c|}{ 3-4 times } & \multicolumn{2}{|c|}{$\geq 5$ times } \\
\hline & No. & $\%$ & No. & $\%$ & No. & $\%$ & No. & $\%$ \\
\hline Humiliating & 763 & 71.6 & 134 & 12.6 & 66 & 6.2 & 103 & 9.6 \\
\hline Shouting & 553 & 51.9 & 221 & 20.7 & 129 & 12.1 & 163 & 15.3 \\
\hline Calling names & 681 & 63.9 & 160 & 15.0 & 88 & 8.3 & 137 & 12.8 \\
\hline Embarrassed of being orphan & 1048 & 98.3 & 12 & 1.1 & 3 & 0.3 & 3 & 0.3 \\
\hline Embarrass of being poor & 1009 & 94.7 & 28 & 2.6 & 14 & 1.3 & 15 & 1.4 \\
\hline Threaten with bad marks & 726 & 68.1 & 156 & 14.6 & 87 & 8.2 & 97 & 9.1 \\
\hline Threaten to drop out school & 733 & 68.8 & 180 & 16.9 & 68 & 6.4 & 85 & 7.9 \\
\hline Embarrass by having health problems & 1014 & 95.1 & 26 & 2.4 & 17 & 1.6 & 9 & 0.8 \\
\hline Isolated from children & 992 & 93.1 & 32 & 3.0 & 27 & 2.5 & 15 & 1.4 \\
\hline Destroying belongings & 1045 & 98.0 & 8 & 0.8 & 2 & 0.2 & 11 & 1.0 \\
\hline
\end{tabular}


Table 4 Univariate analysis for pupils' variables and emotional abuse

\begin{tabular}{|c|c|c|c|c|c|}
\hline \multirow[t]{2}{*}{ Variables } & \multicolumn{5}{|c|}{ Emotional abuse } \\
\hline & No & $\%$ & OR & $(95 \% \mathrm{Cl})$ & $P$-value \\
\hline \multicolumn{6}{|l|}{ Gender } \\
\hline Female* & 104 & 26.1 & 1.00 & & \\
\hline Male & 484 & 72.6 & 7.50 & $5.66-9.93$ & .000 \\
\hline \multicolumn{6}{|c|}{ Age group } \\
\hline $12-13^{*}$ & 173 & 47.7 & 1.00 & & \\
\hline $14-15$ & 361 & 58.4 & 1.54 & $1.18-2.00$ & .001 \\
\hline $16-17$ & 54 & 63.5 & 1.91 & $1.17-3.11$ & .009 \\
\hline \multicolumn{6}{|c|}{ School grade } \\
\hline Grade $7^{*}$ & 171 & 53.1 & 1.00 & & \\
\hline Grade 8 & 212 & 57.9 & 1.21 & $.89-1.64$ & .205 \\
\hline Grade 9 & 205 & 54.2 & 1.04 & $.77-1.41$ & .766 \\
\hline
\end{tabular}

* Reference category.

this may account for the reason why boys experience emotional abuse more often than girls from their teachers [31]. Furthermore, it was reported that poor academic performance of male pupils might explain the higher prevalence of emotional abuse among boys. They

Table 5 Univariate analysis for parent's variables and emotional abuse

\begin{tabular}{|c|c|c|c|c|c|}
\hline \multirow[t]{2}{*}{ Variables } & \multicolumn{5}{|c|}{ Emotional abuse } \\
\hline & No & $\%$ & OR & $(95 \% \mathrm{Cl})$ & $P$-value \\
\hline \multicolumn{6}{|l|}{ Family type } \\
\hline Nuclear* & 388 & 51.9 & 1.00 & & \\
\hline Extended & 200 & 62.7 & 1.55 & $1.18-2.03$ & .001 \\
\hline \multicolumn{6}{|c|}{ Father education } \\
\hline Illiterate* & 46 & 62.2 & 1.00 & & \\
\hline Read/write & 162 & 57.7 & 1.28 & $.77-2.13$ & .338 \\
\hline Basic & 61 & 59.2 & 1.06 & $.78-1.44$ & .698 \\
\hline Secondary & 91 & 45.0 & 1.13 & $.73-1.75$ & .575 \\
\hline University & 228 & 56.2 & .64 & $.45-.89$ & .010 \\
\hline \multicolumn{6}{|c|}{ Mother education } \\
\hline Illiterate ${ }^{*}$ & 151 & 57.2 & 1.00 & & \\
\hline Read/write & 190 & 58.6 & 1.28 & $.84-1.93$ & .241 \\
\hline Basic & 95 & 53.7 & 1.35 & $.91-2.02$ & .133 \\
\hline Secondary & 81 & 50.0 & 1.11 & $.71-1.73$ & .647 \\
\hline University & 71 & 51.1 & .95 & $.60-1.50$ & .852 \\
\hline \multicolumn{6}{|c|}{ Parents Marital Status } \\
\hline Married* & 521 & 54.7 & 1.00 & & \\
\hline Separated & 13 & 61.9 & 1.34 & $.55-3.27$ & .515 \\
\hline Divorced & 24 & 72.7 & 2.20 & $1.01-4.79$ & .046 \\
\hline Widow & 30 & 50.0 & .82 & $.49-1.39$ & .476 \\
\hline
\end{tabular}

* Reference category. found that low achieving boys have been more emotionally abused by both male and female teachers compared to girls [29]. Accordingly, we can conclude that gender is a strong predictor of emotional abuse.

With respect to pupils' age group, the findings indicated that the risk of emotional abuse in schools increase when pupils grow up. This result is consistent to what was found in Iran [17]. Pupils aged 16-17 years are typically those who have failed school years and are thus prone to experience emotional abuse, being threatened with school expulsion [17]. Another explanation is that teachers of older pupils use scolding and grades deduction more [25]. Insulting pupils in our study was $28.4 \%$ very much lower than what was reported in an earlier study from Yemen where $42.3 \%$ of the pupils aged 6-15 years old claimed that they were insulted at school when they make a mistake [20].

Emotional abuse is prevalent in $7^{\text {th }}, 8$ th, and $9^{\text {th }}$ grades; however, there was no statistical significant association with school grade, though findings show relatively higher odds among $8^{\text {th }}$ graders. This could be explained by the increasing conflict situations between teachers and the $8^{\text {th }}$ grade pupils because of their higher claims for autonomy. Furthermore, it is well known that early adolescence is often a time of increased emotional sensitivity, and even relatively benign comments by teachers can at times be interpreted by adolescent pupils as offending [26]. Further studies are required to examine more closely the characteristics of abusive teachers' behaviors in relation to the pupils' school grade and age groups.

For the assessment of the prevalence of emotional abuse, it is also important to analyze how the family structure and parent's socio-demographic characteristics may be related to pupil's abuse in schools. In our study,

Table 6 Multivariate analysis for pupils and parents variables with emotional abuse

\begin{tabular}{lccccc}
\hline Variables & \multicolumn{5}{c}{ Emotional abuse } \\
\cline { 2 - 6 } & No. & $\%$ & OR & $\mathbf{( 9 5 . 0 ~ \% ~ C l )}$ & $P$-value \\
\hline Gender & & & & & \\
Female* & 104 & 26.1 & 1.00 & & .000 \\
Male & 484 & 72.6 & 9.94 & $7.19-13.74$ & \\
Family type & & & & & \\
Nuclear* & 388 & 51.9 & 1.00 & & .056 \\
Extended & 200 & 62.7 & 1.40 & $1.02-1.90$ & \\
Father education & & & & .549 \\
Illiterate* & 46 & 62.2 & 1.00 & & .094 \\
Read/write & 162 & 57.7 & .84 & $.46-1.51$ & .967 \\
Basic & 61 & 59.2 & .73 & $.50-1.06$ & .007 \\
Secondary & 91 & 45.0 & .99 & $.60-1.65$ & \\
University & 228 & 56.2 & .58 & $.39-.86$ & \\
\hline * Reference category. & & & &
\end{tabular}

* Reference category. 
we examined the relationship between the prevalence of emotional abuse in a school and the educational level, family type, and marital status of the pupil's parents.

The study findings showed that pupils living in extended families have higher odd of reporting being emotionally abused at school. This could be interpreted according to the social learning theory, where pupils from extended families live in crowded homes and witness family violence. In addition, children remain outdoors long hours observing and imitating aggressive behaviors that affects their relationship with teachers and make them at higher risks of emotional abuse [32].

The study findings revealed that pupils whose parents have low education level, exhibited higher odds of emotional abuse but was not statistically significant.

Parents with low education level may be less able to avail themselves of resources for coping with family problems, avoiding abusive relationships, and for that, they solve their problems aggressively [33]. Children of those families usually witness violence at home, which negatively influence their behavior at school and make them at higher risks of abuse. The findings of our study indicate that the higher education level of fathers play a protective role against child abuse at school.

\section{Conclusion}

Emotional abuse of schoolchildren is a highly prevalent problem with social, cultural and health dimensions. Child gender, family type, and father's education level were the main predictors for emotional abuse. Accordingly, appropriate social, legislative and administrative interventions at the family, school and community levels are essential to deal with the problem of schoolchildren emotional abuse by their teachers. Further studies at a national level are required for better understanding the different dimensions of this problem.

\section{Competing interests}

The authors declare that they have no competing interests.

\section{Authors' contributions}

ASS, carried out the design of the study, collected the data, completed all statistical analyses, interpreting the data, and drafted the manuscript. ASH, has been actively involved in drafting the manuscript and revising it critically for important intellectual content; and has given final approval of the version to be published.

\section{Received: 10 February 2012 Accepted: 27 July 2012}

Published: 13 August 2012

\section{References}

1. McEachern A, Aluede O, Kenny M: Emotional abuse in the classroom: Implications and interventions for counselors. J Couns Dev 2008, 86:3-10.

2. Aluede O: Psychological Maltreatment of Students: A Form of Child Abuse and School Violence. J Hum Ecol 2004, 16:265-270.

3. Yates TM: The developmental consequences of child emotional abuse: $A$ neurodevelopmental perspective. J Emo Abuse 2007, 7:9-34

4. Brendgen M, Wanner B, Vitaro F: Verbal Abuse by the Teacher and Child Adjustment from Kindergarten through Grade 6. Pediatrics 2006, 117:1585-1598.
5. Shaffer A, Yates TM, Egeland BR: The relation of emotional maltreatment to early adolescent competence: Developmental processes in a prospective study. Child Abuse Negl 2009, 33:36-44.

6. Hart SN, Brassard MR, Binggeli NJ, Davidson HA: Psychological maltreatment. In The APSAC handbook on child maltreatment. 2nd edition. Edited by Myers JE, Berliner L, Briere J, Hendrix CT, Jenny C, Reid TA. Thousand Oaks: Sage Publications; 2002:79-104.

7. Brassard MR, Donovan KL: Defining psychological maltreatment. In Child abuse and neglect: Definitions, classifications, and a framework for research. Edited by Freerick MM, Knutson JF, Trickett PK, Flanzer SM. Baltimore: Brookes Publishing; 2006:151-197.

8. Chianu E: Two deaths, one blind eye, one imprisonment: Child abuse in the guise of corporal punishment in Nigerian schools. Child Abuse Negl 2000, 24:1005-1009.

9. Dupper DR, Dingus AEM: Corporal punishment in U.S. public schools: A continuing challenge for school social workers. Child Sch 2008, 30:243-250

10. Youssef RM, Attia MS, Kamel Ml: Children experiencing violence II: prevalence and determinants of corporal punishment in schools. Child Abuse Negl 1998, 22:975-985.

11. Kacker L, Varadan S, Kumar PK: Study on Child Abuse - India 2007. New Delhi: Kiriti; 2007

12. Whitted KS, Dupper DR: Do Teachers Bully Students? Findings from a survey of students in an alternative education setting. Educ Urb Soc 2008, 40:329-341.

13. Shumba A: The nature, extent and effects of emotional abuse on primary school pupils by teachers in Zimbabwe. Child Abuse Negl 2002, 26:783-791.

14. Okoza J, Aluede O, Ojugo A: Sex and Class of Secondary School Students in Experiencing Emotional Abuse by Teachers in Edo State, Nigeria. J Soc Sci Hum 2011, 19:385-392.

15. Theoklitou D, Kabitsis N, Kabitsi A: Physical and emotional abuse of primary school children by teachers. Child Abuse Negl 2012, 36:64-70.

16. Al Mahroos F: Corporal punishment and psychological maltreatment among schoolgirls in Bahrain. Bahrain Med Bull 1997, 19(Suppl 3):70-73.

17. Sheikhattari P, Stephenson R, Assasi N, Eftekhar H, Zamani Q, Maleki B, Kiabayan $\mathrm{H}$ : Child maltreatment among school children in the Kurdistan Province, Iran. Child Abuse Negl 2006, 30:231-245.

18. Alyahri A, Goodman R: Harsh corporal punishment of Yemeni children: Occurrence, type and associations. Child Abuse Negl 2008, 32:766-773.

19. Basaddik A: Prevalence of child abuse in Aden governorate. Aden University: Social Medicine and Public Health Department; 2007. MD thesis.

20. Al-Dabhani N: Violence against children in selected areas of Yemen. Sana'a: Graphics International Press; 2005.

21. International Society for prevention of child abuse and neglect: Child Abuse Screening Tool-Children's Institutional Version (ICAST-CT); 2007. www.ispcan.org/.

22. Straus MA: New scoring methods for violence and new norms for the Conflict Tactics Scale. In Physical violence in American families. Edited by Straus MA, Gelles RJ. New Brunswick: Transaction Publishers; 1992:529-559.

23. Chen J, Wei H: Student victimization by teachers in Taiwan: Prevalence and associations. Child Abuse Negl 2011, 35:382-390.

24. Egeland B: Taking stock: Childhood emotional maltreatment and developmental psychopathology. Child Abuse Negl 2009, 33:22-26.

25. Plan Philippines: Toward a Child-Friendly Education Environment: A Baseline Study on Violence against Children in Public Schools. 2009. http://planinternational.org/learnwithoutfear/resources/publications/philippines-report].

26. Sebre S, Sprugevica L, Novotni A, Bonevski D, Pakalniskiene V, Popescu D, Turchina T, Friedrich W, Lewis O: Cross-cultural comparisons of childreported emotional and physical abuse: rates, risk factors and psychosocial symptoms. Child Abuse Negl 2004, 28:113-127.

27. Kim D, Kim K, Park Y, Zhang LD, Lu MK, Li D: Children's experience of violence in Chin and Korea: A Transcultural study. Child Abuse Negl 2000, 24:1163-1173.

28. Delfabbro P, Winefield T, Trainor S, Dollard M, Anderson S, Metzer J, Hammarstrom A: Peer and teacher Bullying/Victimization of south Australian secondary school students: Prevalence and psychosocial profiles. Br J Educ Psychol 2006, 76:71-90.

29. Hughes JN, Cavell TA, Willson V: Further support for the developmental significance of the quality of the teacher-student relationship. J Sch Psychol 2001, 39:288-301. 
30. Kesner JE: Teacher characteristics and the quality of child-teacher relationship. J Sch Psychol 2000, 38:133-149.

31. De Zolt DM, Hull SH: Classroom and school climate. In Encyclopedia of women and gender. Edited by Worrell J. San Diego: Academic Press; 2000.

32. Newberger EH: Child abuse. In Public Health \& Preventive Medicine. 14th edition. Edited by Wallace RB, Doebbeling BN. US: Appeleton \& Lang; 1998:1241-1260

33. Cox CE, Kotch JB, Everson MD: A longitudinal study of modifying influences in the relationship between domestic violence and child maltreatment. J Fam Violence 2003, 18:5-17.

doi:10.1186/1471-2458-12-647

Cite this article as: Ba- Saddik and Hattab: Emotional abuse towards children by schoolteachers in Aden Governorate, Yemen: A crosssectional study. BMC Public Health 2012 12:647.

\section{Submit your next manuscript to BioMed Central and take full advantage of:}

- Convenient online submission

- Thorough peer review

- No space constraints or color figure charges

- Immediate publication on acceptance

- Inclusion in PubMed, CAS, Scopus and Google Scholar

- Research which is freely available for redistribution 